J. Lake Sci. (湖泊科学), 2011, 23(5):695-700

http: //www. jlakes.org. E-mail: jlakes@niglas.ac.cn

(C) 2011 by Journal of Lake Sciences

\title{
洞庭湖平原中小型湖群沉积物中砷污染特征与评价 ${ }^{*}$
}

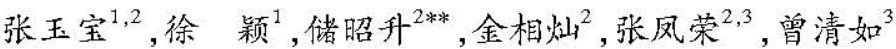 \\ ( 1 : 辽宁工程技术大学资源与环境工程学院,阜新 123000$)$ \\ (2: 中国环境科学研究院湖泊生态环境创新基地, 北京 100012) \\ ( 3 :湖南农业大学资源环境学院, 长少 410128)
}

摘 要: 本文研究了洞庭湖平原 10 个中小型湖泊沉积物砷的空间分布特征, 并采用地累积指数法对其污染进行了评价. 结果表明:各湖表层沉积物中砷浓度在 $10.1-33.7 \mathrm{mg} / \mathrm{kg}$ 之间变化,平均值为 $15.8 \mathrm{mg} / \mathrm{kg}$, 砷含量水平较低; 在空间上表 层沉积物中砷含量次序为岳阳南湖 > 芭蕉湖 > 黄盖湖 > 安乐湖 >毛里湖 > 柳叶湖 > 东湖 > 删珀湖 > 大通湖 > 北民湖, 表现为澧水水系湖泊 (均值 $13.1 \mathrm{mg} / \mathrm{kg}$ ) 和藕池河水系湖泊 (均值 $13.4 \mathrm{mg} / \mathrm{kg}$ ) <沅水水系湖泊 (均值 $16.2 \mathrm{mg} / \mathrm{kg}$ ) <洞 庭湖湖口附近湖泊 (均值 $22.4 \mathrm{mg} / \mathrm{kg}$ ), 基本遵循从洞庭湖水系上游到下游逐渐加重的趋势; 大通湖、黄盖湖、芭蕉湖和册 珀湖 4 个湖泊柱状样数据显示洞庭湖区中小型湖泊沉积物中砷有一定的累积作用; 地累积指数评价结果显示洞庭湖平原 各中小型湖泊表层沉积物中砷污染总体较轻, 其中 8 个湖泊 22 个点位没有污染, 5 个湖泊 7 个点位属于轻度污染.

关键词 : 砷;沉积物; 湖泊群; 洞庭湖平原

\section{Characteristics and evaluation of As pollution in the sediments of medium-small scale lakes in Lake Dongting Plain}

\author{
ZHANG Yubao ${ }^{1,2}$, XU Ying ${ }^{1}$, CHU Zhaosheng ${ }^{2}$, JN Xiangcan ${ }^{2}$, ZHANG Fengrong ${ }^{2,3}$ \& ZENG Qingru ${ }^{3}$ \\ (1: College of Resources and Environmental Engineering, Liaoning Technical University, Fuxin 123000, P. R. China) \\ (2: Research Center of Lake Eco-Environments, Chinese Research Academy of Environmental Sciences, Beijing 100012, P.R. \\ China) \\ (3: College of Resources and Environment, Hunan Agricultural University , Changsha 410128, P.R. China)
}

\begin{abstract}
Spatial distribution of arsenic (As) concentrations of sediments collected form ten medium-small scale lakes in Lake Dongting Plain was investigated, and the As pollution degree was evaluated using the geo-accumulation index. Average value of As sediment concentration from 10 lakes was $15.8 \mathrm{mg} / \mathrm{kg}$, which varied from 10.1 to $33.7 \mathrm{mg} / \mathrm{kg}$. It indicated that As sediment contamination was relative low. As to spatial distributions, the average contents of As in the superficial sediments were from high to low in the sequence of Yueyang South Lake, Bajiao Lake, Huanggai Lake, Anle Lake, Maoli Lake, Liuye Lake, Dong Lake, Shanpo Lake, Datong Lake, and Beimin Lake. As concentrations in the lake basins were from low to high in sequence of Lishui catchment $(13.1 \mathrm{mg} / \mathrm{kg})$, Ouchi catchment $(13.4 \mathrm{mg} / \mathrm{kg})$, Yuanshui catchment $(16.2 \mathrm{mg} / \mathrm{kg})$, and lakes at outlet areas of Dongting Lake $(22.4 \mathrm{mg} / \mathrm{kg}$ ). Degree of As pollution in lake sediments aggravated gradually from the upstream to the downstream of Lake Dongting drainage. Sediment sample analysis from 4 cores (Datong Lake, Huanggai Lake, Bajiao Lake and Shanpo Lake) showed that As had accumulated in sediments and increased from the bottom to the surface $(30-0 \mathrm{~cm})$. Geo-accumulation index analysis showed that pollution level at 22 sites from eight lakes were none, and 7 sites from five lakes were at Level I. As a whole of Lake Dongting drainage, As pollution level in the superficial sediments was low.
\end{abstract}

Keywords; Arsenic; sediment; lake group; Lake Dongting Plain

* 科技部科技基础性工作专项项目 (2006FY110600) 和国家“973”计划项目 (2012CB417004) 联合资助. 2010-09-20 收稿; 2011-03-17 收修改稿. 张玉宝,男, 1985 年生, 硕士研究生; E-mail ; zhangybao@ 163.com.

** 通讯作者; E-mail : chuzs@ craes. org. cn. 
中国是一个湖泊众多的国家, 面积大于 $1 \mathrm{~km}^{2}$ 的湖泊有 2759 个, 总面积达 $91019 \mathrm{~km}^{2}$, 约占全国国土面 积的 $0.8 \%$, 其中约 $1 / 3$ 的湖泊是淡水湖泊 ${ }^{[1]}$. 但是随着社会经济的发展, 湖泊出现了一系列环境问题 ${ }^{[2]}$, 重 金属污染是其中的突出问题之一 ${ }^{[3.6]}$. 砷对水生动植物、土壤微生物及人体产生广泛的毒性并可通过食物链 在生物间传递与富集, 对生物体及生态系统有较大的生态危害性 ${ }^{[7-10]}$. 大量的含䂗粉尘、废水及固体废物排 人环境中, 通过各种途径进人湖泊, 最终沉积于沉积物中. 因此, 湖泊沉积物中砷的污染具有重要的环境指 示意义.

洞庭湖平原位于湖南省北部、长江中游南岸,面积 $12690 \mathrm{~km}^{2}$ (湖南省境内), 是全国三大平原之 长江中下游平原的重要组成部分. 由于洞庭湖平原湖泊群上游采矿、冶金、制酸等工业较多,也曾发生砷污 染事件, 因此洞庭湖平原区重金属污染状况一直是科研工作者关注的重点 ${ }^{[11]}$. 然而, 研究重点大都集中于洞 庭湖, 而对洞庭湖平原上中小型湖泊研究较少. 本文对洞庭湖平原 $10 \mathrm{~km}^{2}$ 以上的中小型湖泊沉积物进行采 样, 研究湖群沉积物中砷的空间分布特征, 并对其污染水平进行评价.

\section{1 材料与方法}

\section{1 样品的采集}

于 2007 年 11 月,采集洞庭湖平原 $\left(28^{\circ} 48^{\prime} 57^{\prime \prime}-29^{\circ} 44^{\prime} 26^{\prime \prime} \mathrm{N}, 111^{\circ} 44^{\prime} 8^{\prime \prime}-113^{\circ} 33^{\prime} 20^{\prime} \mathrm{E}\right)$ 中小湖泊 $\left(10-200 \mathrm{~km}^{2}\right)$ 沉 积物,一共 10 个湖泊 (图 1), 基本情况见表 1 . 根据各湖泊水体的湖库面积、湖盆形态等因素对所研究湖泊 按均匀布点的原则布点 (图 1), 共采集表层 $(0-10 \mathrm{~cm}$ ) 沉积物样品 29 个; 另外选择洞庭湖上游澧水水系珊

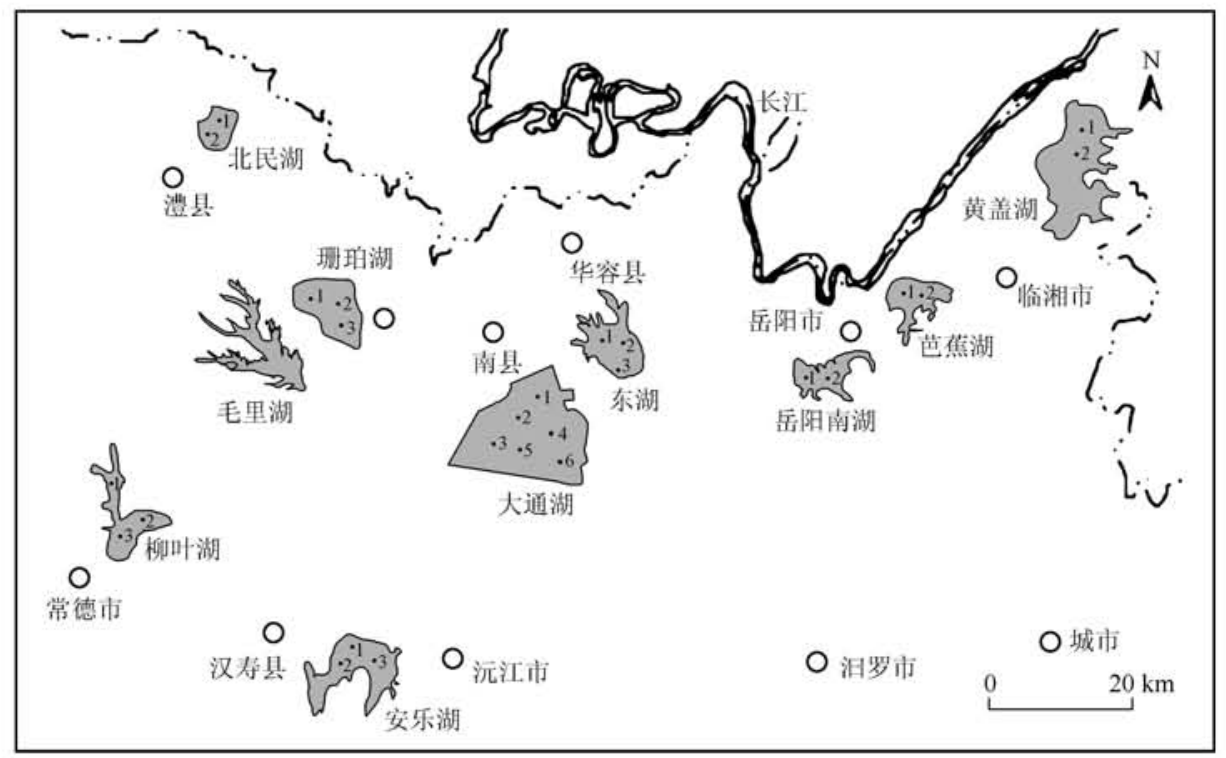

图 1 洞庭湖平原区中小型湖泊及点位分布图

Fig. 1 The distribution of medium-small scale lakes in Lake Dongting Plain and sampling sites

表 1 洞庭湖平原区中小型湖泊基本情况

Tab. 1 The basic situation of medium-small scale lakes of Lake Dongting Plain

\begin{tabular}{|c|c|c|c|c|c|c|c|c|c|c|}
\hline 项目 & 珊暏湖 & 安乐湖 & 毛里湖 & 北民湖 & 柳叶湖 & 东湖 & 大通湖 & 芭蕉湖 & 岳阳南湖 & 黄盖湖 \\
\hline 面积 $\left(\mathrm{km}^{2}\right)$ & 26 & 30 & 36.8 & 14.5 & 24 & 23.2 & 110 & 12.3 & 12 & 86 \\
\hline 水深(m) & 2 & $1-3$ & $3-7$ & $1-3$ & $2-3$ & $2-4$ & $2-3$ & $2-3$ & $2-7$ & $0.3-1$ \\
\hline 透明度 $(\mathrm{m})$ & $0.3-0.5$ & $0.4-1.1$ & $0.3-0.7$ & $0.3-0.7$ & $0.2-0.4$ & $0.3-0.5$ & $0.3-0.7$ & \multicolumn{3}{|c|}{$0.3-0.50 .4-0.60 .3-0.7$} \\
\hline 水系 & 澧水水系 & 沅水水系 & 埧水水系 & 浀水水系 & 沅水水系 & 藕池河水系 & 藕池河水系 & 洞庭湖口 & 洞庭湖口 & 洞庭湖口 \\
\hline
\end{tabular}


表 2 不同水系沉积物中化学组分 $(\%)$

Tab. 2 The compounds in sediments from different water systems (\%)

\begin{tabular}{lccccccccccc}
\hline 水系 & $\mathrm{SiO}_{2}$ & $\mathrm{Al}_{2} \mathrm{O}_{3}$ & $\mathrm{Fe}_{2} \mathrm{O}_{3}$ & $\mathrm{CaO}$ & $\mathrm{MgO}_{2}$ & $\mathrm{~K}_{2} \mathrm{O}$ & $\mathrm{TiO}_{2}$ & $\mathrm{Na}_{2} \mathrm{O}$ & $\mathrm{P}_{2} \mathrm{O}_{5}$ & $\mathrm{MnO}$ & $\mathrm{S}$ \\
\hline 洞庭湖湖口(芭蕉湖) & 57.07 & 19.86 & 5.28 & 0.918 & 1.89 & 2.23 & 0.725 & 0.968 & 0.154 & 0.119 & 0.0533 \\
藕池河水系(大通湖) & 45.67 & 19.47 & 6.12 & 5.47 & 3.03 & 2.75 & 0.824 & 0.735 & 0.351 & 0.100 & 0.1180 \\
澧水水系(珊珀湖) & 50.34 & 18.94 & 5.98 & 4.66 & 3.21 & 2.70 & 0.886 & 0.806 & 0.521 & 0.127 & 0.0853 \\
沅水水系(柳叶湖) & 56.26 & 20.39 & 5.21 & 0.460 & 1.80 & 2.70 & 0.638 & 0.454 & 0.229 & 0.139 & 0.0871 \\
\hline
\end{tabular}

珀湖以及藕池河大通湖, 洞庭湖湖口区的芭蕉湖和黄盖湖 4 个非城市湖泊, 采集沉积物柱状样品(四个水䒺 沉积物的化学组分见表 2); 表层沉积物采用彼得森采样器, 柱状沉积物采用 Beeker 原状采样器采集. 表层 沉积物样品在采集现场迅速装人聚乙烯自封袋里, 柱状样品现场分切后装人聚乙烯自封袋里, 所有样品放 人低温保温箱,迅速带往实验室冷冻备用.

\section{2 样品的测定}

沉积物样品于 $-45^{\circ} \mathrm{C}$ 冷冻干燥、除杂、混合均匀, 用玛瑙研钵磨细后过 100 目尼龙篣. 过篮样品采用王水 沸水浴消解, 消解后定容至 $25 \mathrm{ml}$, As 采用原子苂光光度法测定 (AFS920, 北京吉天). 每个水系选取一个沉 积物样品,采用 X 射线苂光光谱仪 (ARL ADVANT XP +, Thermo electron corporation)测其化学组成. 实验所 用试剂全部为优级纯, 试剂溶液均用去离子水配制, 玻璃、塑料器血均在 $10 \% \mathrm{HNO}_{3}$ 中浸泡 $24 \mathrm{~h}$ 以上, 并用 去离子水洗净烘干; 在整个实验操作过程中, 严格避免接触金属物品. 测定中每批样品做 2 个沉积物标准样 品, 标准样品分析误差需小于 $10 \%$; 样品重复率为 $20 \%$, 重复样间差值小于 $10 \%$.

\section{3 地累积指数法评价砷的污染状况}

沉积物 As 污染采用地累积指数 $I_{\text {geo }}$ (Geoaccumulation Index $)^{[12-13]}$ 进行评价:

$$
I_{\text {geo }}=\lg \frac{C_{n}}{1.5 \times B E_{n}}
$$

式中, $C_{n}$ 为细粒沉积物 ( $<100$ 目) 中元素 $n$ 的浓度; $B E_{n}$ 为元素 $n$ 的地球化学背景浓度; 1.5 为系数, 是考虑 到由于成岩作用可能会引起背景值的变动. 有研究表明在研究某地区沉积物中重金属的地累积指数时,应 以该地区沉积物自身背景值作为计算地累积指数的地球化学背景值 ${ }^{[14]}$. 本文以洞庭湖水系沉积物砷元素背 景值 ${ }^{[15]} 12.9 \mathrm{mg} / \mathrm{kg}$ 作为洞庭湖平原湖区中小湖泊的环境背景值. 根据地质累积指数的大小, Muller 将地累 积指数划分为 7 个等级 ${ }^{[12]}$ (表 3$)$.

表 3 地累积指数 $I_{\text {geo }}$ 与污染程度分级

Tab.3 $I_{\text {geo }}$ and the pollution degree

\begin{tabular}{cccccccc}
\hline 级别 & 0 & I & II & III & IV & V & VI \\
\hline$I_{\text {geo }}$ 指数 & $<0$ & $0-1$ & $1-2$ & $2-3$ & $3-4$ & $4-5$ & $>5$ \\
污染程度 & 清洁 & 轻度污染 & 偏中度污染 & 中度污染 & 偏重污染 & 重污染 & 严重污染 \\
\hline
\end{tabular}

\section{2 结果与分析}

\section{1 沉积物中砷的空间分布特征}

洞庭湖平原 10 个中小型湖泊不同点位表层沉积物中砷含量及其均值如图 2 所示. 表层沉积物中砷含量 差别较大, 在 $10.1-33.7 \mathrm{mg} / \mathrm{kg}$ 之间, 平均值为 $15.8 \mathrm{mg} / \mathrm{kg}$, 最低点是北民湖的 $1^{*}$ 点, 最高点是岳阳南湖的 $2^{*}$ 点. 各湖表层沉积物中砷平均含量次序为: 岳阳南湖 > 芭蕉湖 > 黄盖湖 > 安乐湖 >毛里湖 $>$ 柳叶湖 >东湖 $>$ 册珀湖 > 大通湖 > 北民湖. 在同一个湖泊, 不同湖区砷含量差异也较大, 如岳阳南湖东部高于西部近 $60 \%$. 各水系之间表现为澧水水系湖泊 (北民湖、栅珀湖、毛里湖), 藕池河水系湖泊 (大通湖、东湖) 低于沅水 
水系湖泊 (柳叶湖、安乐湖), 低于洞庭湖湖口区湖泊 (岳阳南湖、芭蕉湖、黄盖湖), 这些水系沉积物砷含量 分别为 $13.1 、 13.4 、 16.2 、 22.4 \mathrm{mg} / \mathrm{kg}$, 大体从上游至下游逐渐增高. 从沉积物化学组成看, 砷含量较高的沅 水水系及洞庭湖湖口区湖泊沉积物, 其硅铝酸盐含量也明显较澧水水系和藕池河水系湖泊沉积物高, 而钙、 镁盐的含量则呈相反的变化, 说明沉积物化学组成也可能是影响沉积物砷污染的一个重要因素.

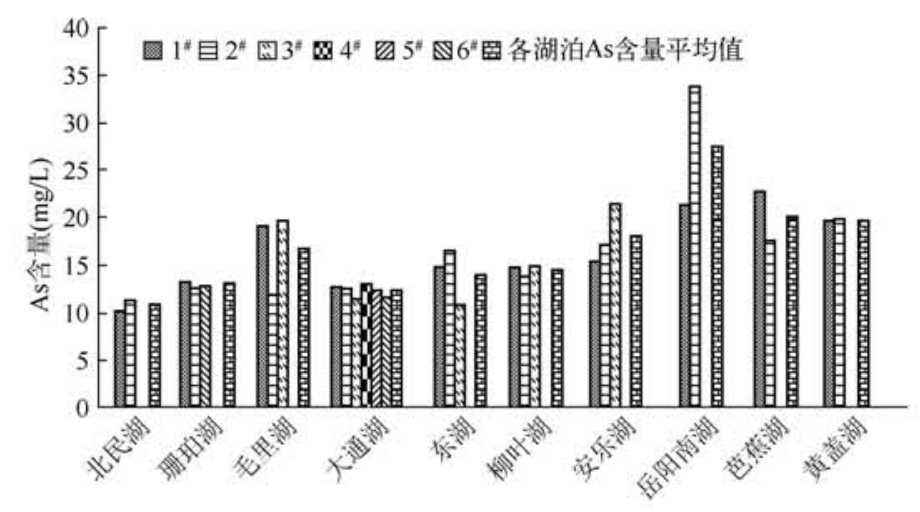

图 2 各湖泊表层沉积物中 As 含量及平均值

Fig. 2 The average values and concentrations of As in superficial sediments of lakes

\section{2 沉积物中重金属含量的垂向变化}

洞庭湖平原 4 个湖泊沉积物柱状样中砷的含量均表现出表层含量升高的现象 (图 3), 洞庭湖湖口区.典

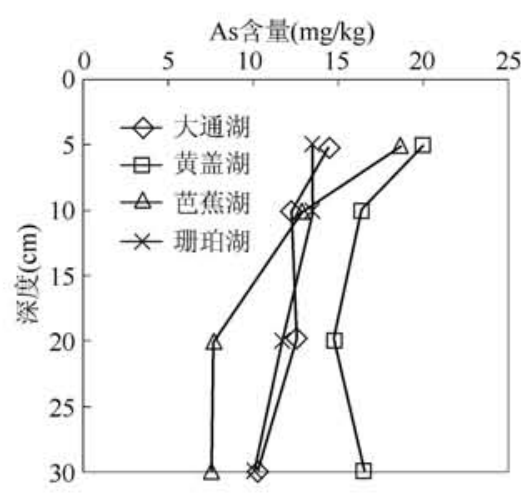

图 3 湖泊柱状沉积物砷含量垂向 分布 $(\mathrm{mg} / \mathrm{kg})$

Fig. 3 Vertical distribution of As concentrations in core sediments of lakes $(\mathrm{mg} / \mathrm{kg})$ 型湖泊芭蕉湖、黄盖湖虽然沉积物中砷含量总体水平不高, 但在 $250-20 \mathrm{~cm}$ 的深度上砷含量向表层快速升高, 尤其是芭蕉湖, 说明 近年来沉积物中砷累积速度加快. 洞庭湖上游藕池河水系典型 湖泊大通湖及澧水水系典型湖泊珊珀湖在 $0-30 \mathrm{~cm}$ 的深度上 向表层也表现出升高趋势, 但相对较为缓慢. 芭蕉湖和黄盖湖位 于洞庭湖水系的下游, 其垂向上砷含量快速升高可能与周边人 类工业活动强度较高有关.

\section{3 湖泊沉积物中砷污染评价}

各湖泊地累积指数表明, 洞庭湖平原中小型湖泊表层沉积物 中砷污染总体较轻, 10 个湖泊 29 个点位中只有 5 个湖泊 7 个点 位有轻度污染 (表 4$)$, 其中 5 个点位分布在洞庭湖湖口区的 3 个 湖泊: 岳阳南湖、芭蕉湖和黄盖湖, 另外 2 个分布在安乐湖和毛里 湖. 柱状样品地累积指数表明芭蕉湖、㑚珀湖和大通湖 $0-30 \mathrm{~cm}$ 深度上都没有污染, 黄盖湖 5-30 $\mathrm{cm}$ 层沉积物也没有污染, 只有 表层 $5 \mathrm{~cm}$ 层有轻度污染, 说明沉积物中砷的总体污染不重, 只是 局部区域近年来污染加重.

\section{3 讨论}

洞庭湖平原区 10 个中小型湖泊表层沉积物砷平均值为 $15.8 \mathrm{mg} / \mathrm{kg}$, 略高于国家一级土壤标准 $(15.0 \mathrm{mg} / \mathrm{kg})$ 和洞庭湖水系的环境背景值 $(12.9 \mathrm{mg} / \mathrm{kg})$, 且地累积指数小于 1 , 可见洞庭湖中小湖群沉积物

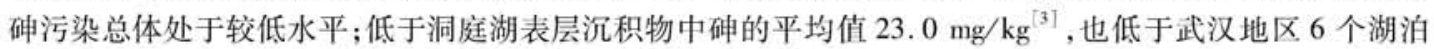
表层沉积物的平均值 $23.6 \mathrm{mg} / \mathrm{kg}^{16]}$. 在空间分布上, 沉积物砷污染呈现从上游至下游增高的趋势, 且可能与 沉积物化学组成中硅铝酸盐及钻、镁盐含量有关. 砷含量较高的沅水水系及洞庭湖湖口区湖泊沉积物, 其硅 铝酸盐含量也明显较澧水水系和藕池河水系湖泊沉积物高, 而钙、镁盐的含量则呈相反的变化, 洞庭湖水系 
中砷主要以溶解态和胶体态存在, 长距离迁移的能力强 ${ }^{[17]}$, 沉积物中矿物成分对砷的迁移、归宿影响可能 较大.

洞庭湖区各湖泊不同点位表层沉积物砷含量与铜、 镍、锌、镉、铬等 5 种重金属含量无显著相关性 $(P>$ $0.05)$, 与铅有显著相关性 $(P=0.02)$ (表 5), 说明砷与 铅的污染可能有同源性. 在洞庭湖平原地区, 影响砷和 铅的空间分布的主要因素可能是环境本底的差异 ${ }^{[16,18]}$ 以及制酸、铅的冶炼等工业污染; 而影响其它金属空间 分布的因素可能主要是矿山开采和金属冶炼等. 近年 来, 洞庭湖区经济发展较快, 但经济发展方式仍较为粗 放, 由于砷属于亲硫元素, 不少硫化矿都伴生有砷, 因 此加强该地区铅锌矿石冶炼、制酸、农药生产等砷排放 企业, 尤其是洞庭湖湖口区及沅江水系砷排放企业的 监控, 是游止洞庭湖平原中小湖群砷污染的关键.

地累积指数法评价表明洞庭湖平原 10 个湖泊 29 个点位中只有 5 个湖泊 7 个点位有轻度污染, 4 个柱状 样中, 也只有黄盖湖表层 $5 \mathrm{~cm}$ 沉积物有轻度污染, 说明 洞庭湖平原湖泊沉积物砷污染总体水平较低. 然而, 地 累积指数法评价砷污染仍有较大的局限性, 砷在水体中 存在的形态较多, 只有 $\mathrm{As}^{3+}$ 危害较大, 而且, $\mathrm{As}^{3+}$ 及 $A \mathrm{~s}^{5}+$ 易于转变,砷污染还存在时间上的差异性.

\section{4 结论}

（1）洞庭湖平原区中小型湖泊表层沉积物中砷污染 水平较轻, 10 个湖泊 29 个点位砷浓度平均值略高于国家 一级土壤标准和土壤背景值, 平均地累积指数小于 0 .

（2）洞庭湖平原区中小型湖泊表层沉积物中砷平 均含量次序为:岳阳南湖 $>$ 芭蕉湖 $>$ 黄盖湖 $>$ 安乐湖 $>$ 毛里湖 $>$ 柳叶湖 $>$ 东湖 $>$ 珊珀湖 $>$ 大通湖 $>$ 北民湖; 各 水系之间表现为澧水水系湖泊 (北民湖、删珀湖、毛里 湖)、藕池河水系湖泊 (大通湖、东湖) 低于沅水水系湖 泊(柳叶湖、安乐湖), 低于洞庭湖湖口区湖泊(岳阳南

表 4 各湖泊表层沉积物 As 元素地累积指数 及污染等级

Tab. 4 Indices of geoaccumulation and grades for As pollution in superficial sediments

\begin{tabular}{|c|c|c|c|}
\hline 湖泊 & 点位 & 地累积指数 & 污染等级 \\
\hline \multirow{3}{*}{ 安乐湖 } & 1 & -0.34 & 0 \\
\hline & 2 & -0.18 & 0 \\
\hline & 3 & 0.14 & I \\
\hline \multirow[t]{3}{*}{ 东湖 } & 1 & -0.39 & 0 \\
\hline & 2 & -0.24 & 0 \\
\hline & 3 & -0.85 & 0 \\
\hline \multirow[t]{6}{*}{ 大通湖 } & 1 & -0.61 & 0 \\
\hline & 2 & -0.61 & 0 \\
\hline & 3 & -0.77 & 0 \\
\hline & 4 & -0.58 & 0 \\
\hline & 5 & -0.65 & 0 \\
\hline & 6 & -0.75 & 0 \\
\hline \multirow[t]{3}{*}{ 柳叶湖 } & 1 & -0.39 & 0 \\
\hline & 2 & -0.49 & 0 \\
\hline & 3 & -0.38 & 0 \\
\hline \multirow[t]{3}{*}{ 珊珀湖 } & 1 & -0.54 & 0 \\
\hline & 2 & -0.63 & 0 \\
\hline & 3 & -0.61 & 0 \\
\hline \multirow[t]{3}{*}{ 毛里湖 } & 1 & -0.04 & 0 \\
\hline & 2 & -0.72 & 0 \\
\hline & 3 & 0.02 & I \\
\hline \multirow[t]{2}{*}{ 北民湖 } & 1 & -0.93 & 0 \\
\hline & 2 & -0.78 & 0 \\
\hline \multirow[t]{2}{*}{ 岳阳南湖 } & 1 & 0.13 & I \\
\hline & 2 & 0.80 & I \\
\hline \multirow[t]{2}{*}{ 芭蕉湖 } & 1 & 0.23 & I \\
\hline & 2 & -0.15 & 0 \\
\hline \multirow[t]{2}{*}{ 黄盖湖 } & 1 & 0.02 & I \\
\hline & 2 & 0.03 & I \\
\hline
\end{tabular}
湖、芭蕉湖、黄盖湖), 显示从上游向下游增高.

(3) 洞庭湖平原湖群靠城市附近湖泊, 表层沉积物中砷有一定累积.

表 5 不同湖泊表层沉积物中 As 平均含量与其他微量元素(1) 的 Pearson 相关系数 $(n=28)$

Tab. 5 Pearson correlation coefficient of As and other trace metals in superficial sediments of different lakes $(n=28)$

\begin{tabular}{cccccrc}
\hline 微量元素 & $\mathrm{Cu}$ & $\mathrm{Ni}$ & $\mathrm{Zn}$ & $\mathrm{Pb}$ & $\mathrm{Cd}$ & $\mathrm{Cr}$ \\
\hline 相关系数 & 0.18 & 0.11 & 0.05 & $0.45^{*}$ & -0.15 & 0.23 \\
$P$ & 0.35 & 0.59 & 0.81 & 0.02 & 0.46 & 0.91 \\
\hline
\end{tabular}

*表示显著相关, $P<0.05$.

(1) 参照湖泊调查数据. 


\section{5 参考文献}

[1] 王苏民, 窦鸿身主编. 中国湖泊志. 北京: 科学出版社, 1998: 3-21.

[2] 储昭升, 刘文新, 汤鸿霄. 官厅水库一永定河沉积物中 AVS-SEM 的分析. 环境化学, 2003, 22(4): 313-317.

[3] 朱 荁. 中国湖泊环境的保护和管理. 见: 金相灿等编. 中国湖泊环境. 北京: 海洋出版社, 1995: 364-368.

[ 4 ] 曾海鳌, 吴敬禄. 近 50 年来抚仙湖重金属污染的沉积记录. 第四纪研究, 2007, 22(1): 128-132.

[ 5] 乔胜英, 蒋敬业, 向 武等. 武汉地区湖泊沉积物重金属的分布及潜在生态效应评价. 长江流域资源与环境, 2005, 14(3): 353-357.

[6] 陈守莉, 王平祖, 秦明周等. 太湖流域典型湖泊沉积物中重金属污染的分布特征. 江苏农业学报, 2007, 23(2)： 124-130.

[ 7 ] Tessier A, Tumer DR. Metal speciation and bioavailability in aquatic systems. Chichester: John Wiley and Sons, 1995: 670 .

[ 8 ] Saw idis T, Stratis J, Zarhariadis G. Distribution of heavy metals in sediments and aquatic plants of the river Pinios (Center Greece). Science of the Total Environment, 1991, 102:261-266.

[ 9 ] 杨居荣, 葛家满, 张美庆等. 砷及重金属对土壤微生物的影响. 环境科学学报, 1982, 2(3): 190-197.

[10］孟紫强, 孟华千. 砷对人血淋巴细胞转化及合成的效应. 中国环境科学, 1994, 14(2): 134-138.

[11] 祝云龙, 姜加虎, 孙占东等. 洞庭湖沉积物中重金属污染特征与评价. 湖泊科学, 2008, 20(4): 477-485.

[12] Müller G. Index of geoaccumulation in sediments of the Rhine River. Geojournal, 1969, 2: 108-118.

[13] Fö rstner U, Müller G. Concentrations of heavy metals and polycyclic aromatic hycarbons in river sediments : geochemical background, man's influence and environmental impact. Geojournal, 1981, 5: 417-432.

[14] 滕彦国, 度先国, 倪师军等. 应用地质累积指数评价沉积物中重金属污染: 选择地球化学背景的影响. 环境科学 与技术, $2002,25(2): 7-9$.

[15] 李 健, 曾北危, 姚岳云等. 洞庭湖水系水体环境背景值调查研究. 环境科学, 1986:62-68.

[16] 童 霆. 河口三角洲元素含量与矿产资源—以湘资沅澧为例. 第四纪研究, 2005, 25(3): 298-305.

[17] 杨忠芳, 夏学齐, 余涛等. 湖南洞庭湖水系 As 和 Cd 等重金属元素分布特征及输送通量. 现代地质, 2008, $22(6)$ : 897-908.

[18] 章 申, 张立城, 田笠卿等. 化学元素水环境背景值研究. 见: 李 健, 胡冬严编. 洞庭湖水系亲铜成矿元素背 景值的地球化学特征. 北京: 测绘出版社, 1990: 56-63. 